\title{
Simulation of MRAC based speed control of brushless DC motor with low-resolution hall-effect sensors
}

\author{
G.SUNIL ${ }^{1}$, B.RAJASEKHAR ${ }^{2}$ \\ M.E Scholar (Control Systems), EEE, ANITS College, Visakhapatnam, India ${ }^{1}$ \\ M.E (Control Systems), Asst. Professor, EEE, ANITS College, Visakhapatnam, India ${ }^{2}$
}

\begin{abstract}
A novel speed estimation approach with control system based on model reference adaptive control (MRAC) is presented for low cost brushless dc motor drives with low-resolution hall sensors. The back EMF is usually used to estimate speed. But the estimation result is not accurate enough at low speeds because of the divided voltage of stator resistors and too small back EMF. Moreover, the stator resistor is always varying with the motor's temperature. A speed estimation algorithm based on MRAC was proposed to correct the speed error estimated by using back EMF. The proposed algorithm's most innovative feature is its adaptability to the entire speed range including low speeds and high speeds and temperature and different motors do not affect the accuracy of the estimation result. The effectiveness of the algorithm was verified through simulations and experiments.
\end{abstract}

Keywords: Brushless dc motor, low-resolution hall sensor, model reference adaptive control, speed estimation

\section{INTRODUCTION}

Brushless dc (BLDC) motors are preferred as small horsepower control motors due to their high efficiency, silent operation, compact form, reliability, and low maintenance. However, the problems are encountered in these motor for variable speed operation over last decades continuing technology development in power semiconductors, microprocessors, adjustable speed drivers control schemes and permanent-magnet brushless electric motor production have been combined to enable reliable, cost-effective solution for a broad range of adjustable speed applications.

Due to the nonlinearity of the motor system, MRAC or model reference adaptive control which is one of a kind in adaptive control techniques is implemented. It is regarded as an adaptive servo system in which the desired performance is expressed in terms of reference model, which gives the desired response to a command signal. The nonlinearity occurs because the system transfer function varies or changes with the speed of the motor and the controller ought to be adaptive and robust for these changes.

Brushless dc (BLDC) motors usually use three or more Hall sensors to obtain rotor position and speed measurement. It would be necessary to inverse the time difference between two successive Hall sensor signals to obtain reliable speed measurement. Notice that there are only a few sensor signals available to the motor at low speeds. There may be 12 or 24 sensor pulses per round which depend on the number of poles. The sampling time, thus, becomes a variable according to the motor speed. These systems have uncertainty in a discrete time model and have a lot of difficulties to design speed regulators. Moreover, the sampling time is too long for speed
Regulations at low speeds. In order to make BLDC motors with low-resolution encoders work at very low speed and reduce the difficulty of speed regulators' design, several methods have been developed to obtain high accurate speed measurement. These methods are commonly addressed as estimation methods. Instantaneous speed estimation based on a reduced-order disturbance torque observer provides the merits of simple structure and easy implementation [1]. But the high gain problem occurs in real application for mechanical noise and oscillation of system. In [2], a reduced-order extended Luenberger observer was proposed to reduce the sensitivity to the instantaneous speed estimation by the variation of the inertia moment. A computationally intensive Kalman filter is successfully used in dealing with velocity transients [3], but it is susceptible to the mismatch of parameters between the filter's model and the motor. In [4], a dual observer was proposed. The dual observer can estimate the rotor speed and position without time delay or bumps. All the observer-based methods share the feature of providing high accuracy of the speed estimation with satisfactory dynamic performance. But they suffer from the dependence on system parameters and need heavy computation [5]. A model free enhanced differentiator is proposed for improving velocity estimation at low speed [6], [7]. But the computation includes the fractional power of variables. Many other authors have suggested that accurate speed estimation can be obtained by using a lowresolution encoder, together with a position extrapolation algorithm, implemented in the drive control processor [8][12]. However, the estimation in [12] was dependent on the accuracy of position sensor and mechanical parameters. Hardware approaches involving a phase locked loop [13], [14] are feasible for a drive running at near-constant velocity, but may be unable to deal with 
transient velocity operation. For BLDC motors, the most popular speed estimation method may be based on back EMF. Operation rotor speeds determine the magnitude of the back EMF. At low speeds, the back EMF is not large enough to estimate the speed and position due to inverter and parameter nonlinearities. This paper presents a MRAC speed estimation algorithm by using the back EMF. The proposed algorithm can compensate the voltage occupied by the stator resistor adaptively at low speeds and is valid over the entire speed range. Moreover, the parameters of the algorithm can be commonly used for different BLDC motors.

\section{DESCRIPTION OF ESTIMATION ALGORITHM}

\section{A. Model of BLDC Motors}

The equivalent circuit of Y-connection BLDC motor is shown in Fig. 1 [15].

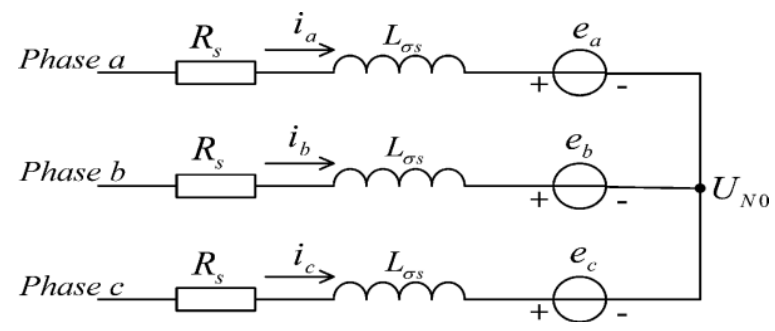

Fig.1.Equivalent circuit of a star connection BLDC motor.

A BLDC motor has three stator windings and permanent magnets on the rotor. Its voltage equation of three windings with phase variables is

$$
\begin{aligned}
& {\left[\begin{array}{l}
v_{a s} \\
v_{b s} \\
v_{c s}
\end{array}\right] } {\left[\begin{array}{ccc}
R_{s} & 0 & 0 \\
0 & R_{s} & 0 \\
0 & 0 & R_{s}
\end{array}\right]\left[\begin{array}{l}
i_{a} \\
i_{b} \\
i_{c}
\end{array}\right]+} \\
& \frac{d}{d t}\left[\begin{array}{lll}
L_{a a} & L_{a b} & L_{a c} \\
L_{b a} & L_{b b} & L_{b c} \\
L_{c a} & L_{c b} & L_{c c}
\end{array}\right]\left[\begin{array}{l}
i_{a} \\
i_{b} \\
i_{c}
\end{array}\right]+\left[\begin{array}{l}
e_{a} \\
e_{b} \\
e_{c}
\end{array}\right]
\end{aligned}
$$

and the electromagnetic torque equation is

$$
\mathrm{T}_{\mathrm{e}}=\left(\mathrm{e}_{\mathrm{a}} \mathrm{i}_{\mathrm{a}}+\mathrm{e}_{\mathrm{b}} \mathrm{i}_{\mathrm{b}}+\mathrm{e}_{\mathrm{c}} \mathrm{i}_{\mathrm{c}}\right) / \omega_{\mathrm{m}}
$$

Where $\mathrm{u}_{\mathrm{a}}, \mathrm{u}_{\mathrm{b}}$ and $\mathrm{u}_{\mathrm{c}}$ are the terminal phase voltages with respect to the power ground, $R s$ is the stator resistance of phase windings, $i a$, $i b$ and $i c$ are phase current, $L \sigma s=L$

- $L m$ is the equivalent inductance of phase windings, $L s$ and $L m$ are self inductance and mutual inductance, respectively, $e a, e b$ and $e c$ are trapezoidal back EMFs, $\mathrm{U}_{\mathrm{NO}}$ is the neutral point to ground voltage, and $\omega_{\mathrm{m}}$ is the speed of the rotor. As a BLDC motor, there are only two phases which have current at the same time. For this analysis, the current from phase $a$ to phase $b$ is considered. There are following equations: rotor given as motor

and the line voltage between phase $a$ and phase $b$ is

$\mathrm{u}_{\mathrm{ab}}=\mathrm{u}-\mathrm{u}_{\mathrm{b}}=2 \mathrm{R}_{\mathrm{s}} \mathrm{i}_{\mathrm{a}}+2 \mathrm{~L} \sigma s \frac{d i_{a}}{d t}+2 \mathrm{e}_{\mathrm{a}}$

Because the rotor of a BLDC motor is permanent magnet, the back EMFs are proportional to the electric speed of the

$$
e_{a}=-e_{b}=k_{e} \omega_{r}
$$

where $k e$ is back EMF coefficient and is a constant. According to (4) and (5), the speed of the rotor can be

$$
\omega_{m}=\left(\mathrm{u}_{\mathrm{ab}}-2 \mathrm{R}_{\mathrm{s}} \mathrm{i}_{\mathrm{a}}-2 \sigma s \frac{d i_{a}}{d t}\right) / \mathrm{pk}_{\mathrm{e}}
$$

and $\omega_{r}=\mathrm{p} \omega_{m} / 2$, where $p$ is the number of poles of a

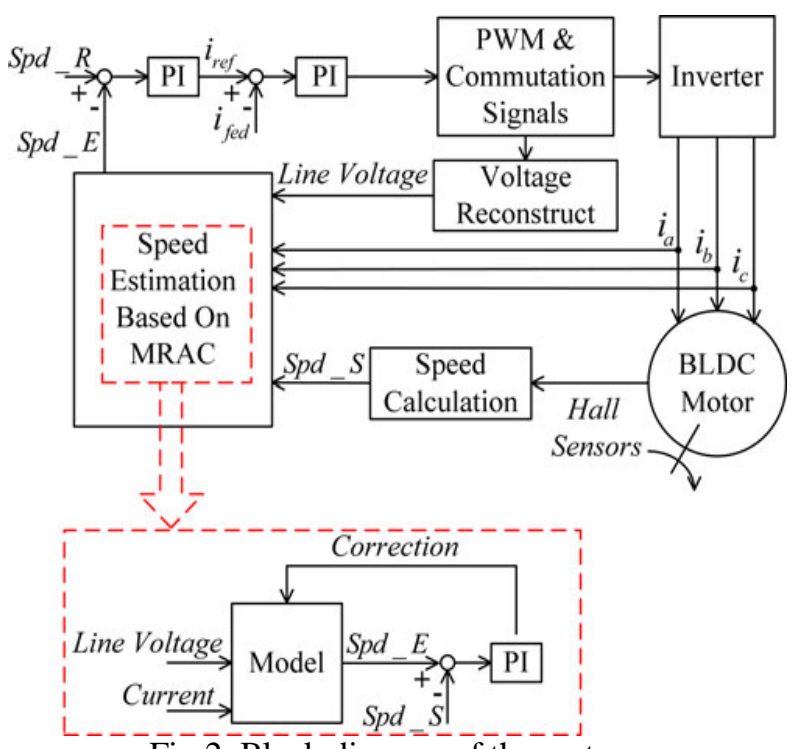

Fig. 2 . Block diagram of the system

In stable condition or when $i a$ is changed very slowly $d i a / d t \approx 0$. Then, (6) can be rewritten as

$$
\omega_{m}=\left(\mathrm{u}_{\mathrm{ab}}-2 \mathrm{R}_{\mathrm{s}} \mathrm{i}_{\mathrm{a}}\right) / \mathrm{pk}_{\mathrm{e}}
$$

\section{B. Speed Estimation}

The speed of the rotor can be calculated by voltage and current without Hall sensors with reference to (7). The line voltage $u_{a b}$ can be estimated by pulse width modulation (PWM) signals. The phase current $i_{a}$ can be 
sensed from hardware. $\mathrm{R}_{\mathrm{s}} \mathrm{i}_{\mathrm{s}}$ a parameter of the motor and is proportional to the temperature. If the change of $R s$ is neglected, the estimated speed is very accurate especially at high speed but when a motor is working at low speed, the estimated speed is not accurate enough. It is mainly because the back EMF is too small comparing with $\mathrm{R}_{\mathrm{s}} \mathrm{i}_{\mathrm{a}}$. A small error of $\mathrm{u}_{\mathrm{ab}}$ or Rs ia would lead to an inaccuracy of the estimated speed. $p$ and $\mathrm{k}_{\mathrm{e}}$ in (7) are constant for a known BLDC motor. But they are changed with different BLDC motors. Actually, $p$ is usually on the plate of a motor and can be obtained easily. $\mathrm{k}_{\mathrm{e}}$, however, is seldom on the plate. Thus, there are two problems with the speed estimation based on the back EMF of BLDC motors. 1) The accuracy of the estimated speed is not enough at low speed and 2) $R s$ is not constant. It is varying by temperature. $p$ and $\mathrm{k}_{\mathrm{e}}$ are variables for different motors. Therefore, the algorithm based on (7) cannot be commonly used for different motors or in different conditions for the same motor.

\section{Basic Idea}

Our objective is to solve these two problems mentioned above, a speed estimation algorithm based on MRAC was proposed. Fig. 2 shows the block diagram of the speed control system with the proposed speed estimation algorithm. It consists of a power circuit and control circuits which perform following functions: PWM strategy, current control, current commutation, speed estimation, and speed control.

The main blocks of the speed estimation is a MRAC-based regulator. The speed estimated by the back EMF and the speed calculated by Hall sensors are the inputs of the regulator. The output of the regulator is a correction variable for the estimated speed. $S p d \_E$ is the estimated speed. Spd_S is the calculated speed by Hall sensors. If $S p d \_E$ is not equal to $S p d \_S$, a correction is given by the PI regulator and then, $S p d \_E$ is calculated again based on the proposed model. The reference current iref is changed by the speed regulator. Through the current regulator, the output voltage of the inverter is being tuned and $S p d \_S$ is changed. In this way, the PI regulator used in the estimation Algorithm is always working until $S p d \_E$ equals to $S p d \_S$.

Proposed Speed Estimation Algorithm Based on MRAC

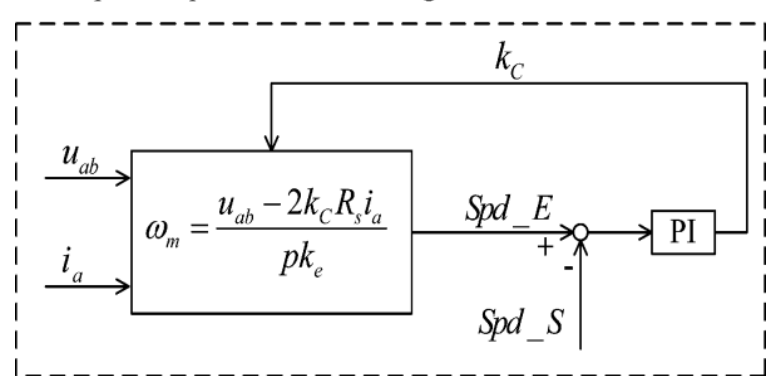

Fig3. Speed estimation algorithm considering the voltage compensation of stator resistor.

The basic block diagram brushless dc motor as shown Fig.4.The brush less dc motor consist of four main parts power converter, permanent magnet-synchronous machine (PMSM) sensors and control algorithm. The power converter transforms power from the source to the PMSM which in turn converts electrical energy to mechanical energy.

One of the salient features of the brush less dc motor is the rotor position sensors, based on the rotor position and command signals which may be a torque

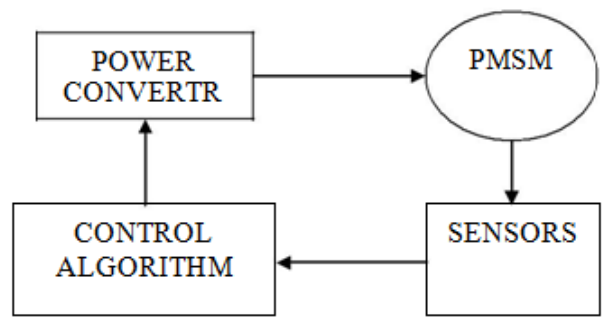

Fig.4 Basic Block Diagram of BLDC motor

command, voltage command, speed command and so on the control algorithms determine the gate signal to each semiconductor in the power electronic converter.

The structure of the control algorithms determines the type of the brush less dc motor of which there are two main classes voltage source based drives and current source based drives. Both voltage source and current source based drive used with permanent magnet synchronous machine with either sinusoidal or nonsinusoidal back emf waveforms .Machine with sinusoidal back emf may be controlled so as to achieve nearly constant torque. However, machine with a non sinusoidal back emf offer reduces inverter sizes and reduces losses for the same power level.

The model reference adaptive system (MRAS) is one of the major approaches for adaptive control. The model reference adaptive system (MRAS) is one of many promising techniques employed in adaptive control. Among various types of adaptive system configuration, MRAS is important since it leads to relatively easy- toimplement systems with high speed of adaptation for a wide range of applications.

One of the most noted advantages of this type of adaptive system is its high speed of adaptation. This is due to the fact that a measurement of the difference between the outputs of the reference model and adjustable model is obtained directly by the comparison of the states (or outputs) of the reference model with those



Fig 5 Basic Block Diagram of MRAS speed estimation 
"reference model" represents demanded of the adjustable system. The block dynamics of actual control loop. The block "adjustable model"' has the same structure as the reference one, but with adjustable parameters instead of the unknown ones.

\section{III.DESIGN OF ESTIMATION ALGORITHM BASED ON MRAC}

For this analysis, the current from phase a to phase b is considered.

\section{A. Speed Estimation Algorithm}

The inaccuracy of the low speed estimation is mainly because of the divided voltage of the stator resistor. So an estimation algorithm considering the voltage compensation of the stator resistor is presented firstly. It is shown in Fig. 3. The estimated speed is calculated by using (7). In Fig. 3, where Rs is not accurate or changed with the temperature, $S p d \_E$ will not be equal to $S p d \_S$. Because $k c$ affects $S p d \_E$ and $S p d \_E$ is the input of the speed PI regulator, the speed PI regulator will change the output voltage to compensate divided voltage of the stator resistor adaptively. $k c$ is always tuning until $S p d \_E$ equals to $S p d \_S$. Therefore, the control system including this proposed speed estimation algorithm can keep the accuracy of the estimated speed at very low speed. The $2 k c R s$ ia not only needs the value of Rs but also needs the value of current. Actually the output of the PI regulator proposed in Fig. 3 can completely compensate the divided voltage of the stator resistor. Therefore, a simple algorithm is proposed in Fig. 6 the $v c$ is the output of the PI regulator and $2 k c R s$ ia is replaced by $v c$.

\section{B. Algorithm Approach Considering Different Motors}

For different motors, the value of $p$ and $k e$ may be changed. $p$ could be easily obtained from the plate of a motor. However, $k e$ is seldom shown on the plate. Therefore, the initial value of ke may be inaccuracy.

\section{Proposed Speed Estimation Algorithm Based on MRAC}

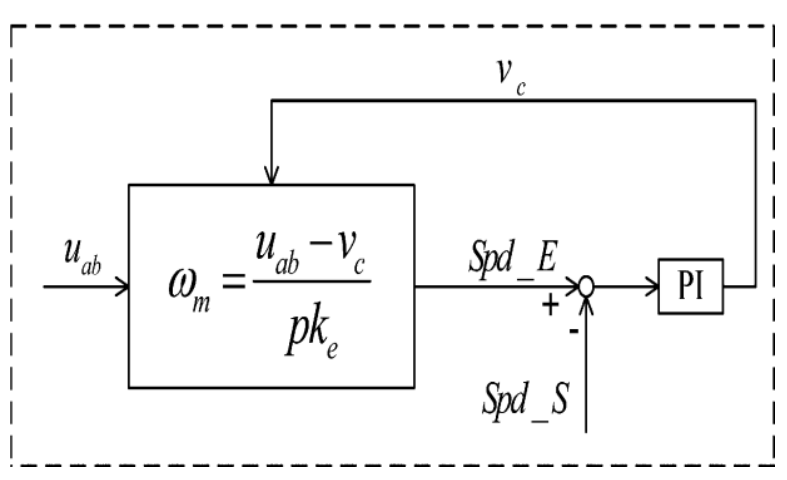

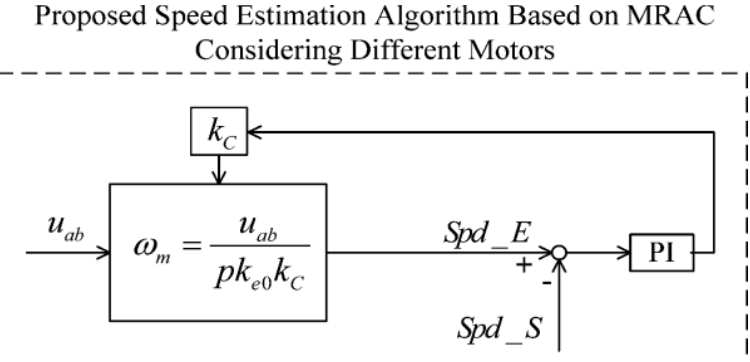

Fig $\overline{7}$. Estimation algorithm approach considering motors at high speed.

At high speed, the divided voltage of stator resistors can be neglected. The voltage on a motor is almost the back EMF. Then, referring to (7), an approach of the high speed estimated algorithm is proposed here.

$$
\omega_{m}=\mathrm{u}_{\mathrm{ab}} / \mathrm{pk}_{\mathrm{e}}
$$

According to (8), ke produces great influence on the accuracy of the estimated result at high speeds. An approach of the high speed estimated algorithm was proposed based on Fig. 6. The block diagram is shown in Fig. 7. $k e 0$ is the initial value of $k e$ and $k e=k e 0 k C$. If $k e 0$ is not accurate, the PI regulator will change the value of $k c$ until $S p d \_E$ equals to $S p d \_S$. In this way, the error of the estimated speed caused by the inaccuracy of $k e$ is corrected by $k c$.

\section{Speed Estimation Algorithm Considering Voltage Compensation and Different Motors}

At low speed, the primary reason of the estimated inaccuracy is the effect of divided voltage on stator resistors. At high speed, the primary reason is the effect of inaccuracy of ke according to different motors. Therefore, a speed threshold is set. If $S p d \_S>S p d \_T \_1$, the estimation algorithm shown in Fig. 7 is used and $k c$ is the output of the regulator to correct the estimated speed. If $S p d \_S<S p d \_T \_2$, the estimation algorithm shown in Fig. 6 is used and $v c$ is the output of the regulator to compensate divided Voltage on stator resistors. Avoiding repeatedly jumping, there is a hysteresis value between $S p d_{-} T_{-} 1$ and $S p d_{-} T_{-} 2$. The selection of $S p d_{-} T_{-} 1$ and $S p d \_T \_2$ is based on the period of speed loop, the number of poles of BLDC, and the number of Hall-effect sensors. Following rules can be used: 1) the longer the period of speed loop, the smaller the value of $S p d_{-} T_{-} 1.2$ ) The more the number of the poles of BLDC motor, the smaller the value of $S p d+T \_1.3$ ) The more the number of Hall-effect sensors, the smaller the value of $S p d_{-} T_{-} 1$. 4) The hysteresis value between $S p d \_T \_1$ and $S p d \_T \_2$ can be selected by experimental results.

The flowchart of estimation algorithm is as shown below

Fig.6. Approach to simplify algorithm. 




Fig.8.Flow chart of estimation algorithm.

\section{SIMULATION RESULTS}

Firstly, outputs of BLDC motor i.e. voltage and current are converted into d-q axis with respective stator are given to Reference and Adaptive model of MRAC. Now these outputs i.e. voltage and current are inputs of MRAC in d-q axis. Finally the output of MRAC is given to PI Controller. By this way BLDC motor speed can be controlled.

The simulation results of MRAC based speed control of Brushless DC Motor with low resolution Hall Effect sensors is as shown below

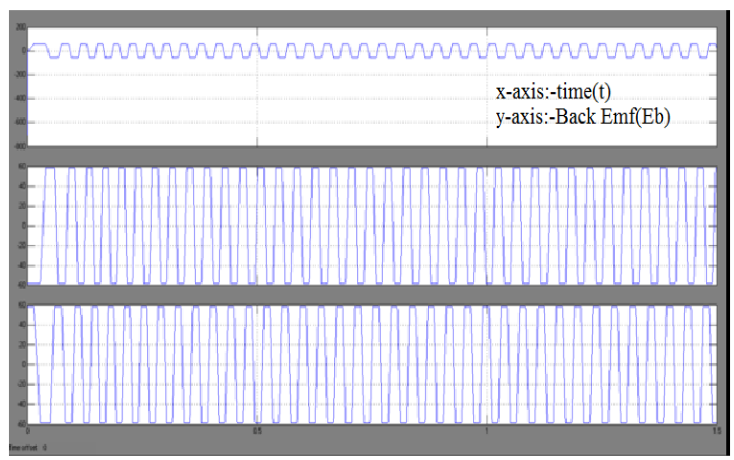

Fig.9.Back emf's of BLDC Motor with MRAC

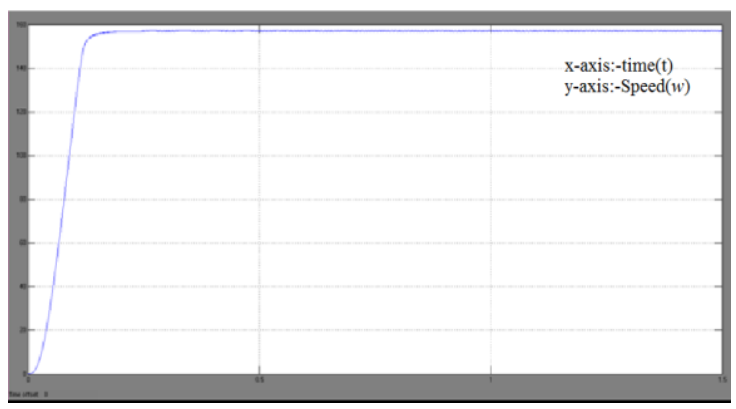

Fig.10.Speed Characteristics of BLDC Motor with MRAC

\section{V.CONCLUSION}

In this paper, a novel speed estimation algorithm based on MRAC is introduced. The proposed algorithm includes two regulators. One regulator corrects back EMF coefficient at high speed. The other regulator compensates the divided voltage of stator resistors at low speed. In this way, the estimation algorithm can work validly at both high speed and very low speed. The drive system with the proposed algorithm widens the speed range of BLDC motors. Moreover, it is not needed to tune parameters according to motors with different back EMF coefficient when using the estimation algorithm.

Extensive simulation have been performed and the results verify that the estimation algorithm proposed in this paper is effective.

\section{REFERENCES}

[1] N. J. Kim, H. S. Moon, and D. S. Hyun, "Inertia identification for the speed control of induction machines," IEEE Trans. Ind. Appl., vol. 32, no. 6, pp. 1371-1379, 1996.

[2] K. B. Lee, J. Y. Yoo, J. H. Song, and I. Choy, "Improvement of low speed operation of electric machine with an inertia identification using ROELO," IEE Proc.-Elect. Power Appl., vol. 151, no. 1, pp. 116-120, 2004

[3] H.-W. Kim and S.-K. Sul, "A new motor speed estimator using Kalman filter in low-speed range," IEEE Trans. Ind. Electron., vol. 43, no. 4, pp. 498-504, Aug. 1996.

[4] A. Yoo, S. K. Sul, D. C. Lee, and C. S. Jun, "Novel speed and rotor position estimation strategy using a dual observer for low resolution position sensors," IEEE Trans. Power Electron., vol. 24, no. 12, pp. 2897-2906, Dec. 2009.

[5] R. Petrella, M. Tursini, L. Peretti, and M. Zigliotto, "Speed measurement algorithms for low resolution incremental encoder equipped drives: A comparative analysis," in Proc. Int. Aegean Conf. Electrical Machines Power Electron, Sep. 2007, pp. 780-787.

[6] Y. X. Su, C. H. Zheng, S. Dong, and B. Y. Duan, "A simple nonlinear velocity estimator for high-performance motion control," IEEE Trans. Ind. Electron., vol. 52, no. 4, pp. 1161-1169, Aug. 2005.

[7] Y. X. Su, C. H. Zheng, P. C. Mueller, and B. Y. Duan, "A simple improved velocity estimation for low-speed regions based on position measurements only," IEEE Trans. Control Syst. Technol., vol. 14, no. 5, pp. 937-942, Sep. 2006.

[8] J. Bu and L. Xu, "Near-zero speed performance enhancement of PM synchronous machines assisted by low-cost Hall effect sensors," in Proc. 13th Ann. IEEE Appl. Power Electron. Conf. Exp., 1998, vol. 1, pp. 64-68.

[9] K. Hyunbae, Y. Sungmo, K. Namsu, and R. D. Lorenz, "Using low resolution position sensors in bump less position/speed estimation methods for low cost PMSM drives," in Proc. IEEE 40th IAS Ann. Meeting Conf. Rec., 2005, vol. 4, pp. 2518-2525.

[10] S.Morimoto, M.Sanada, and T. Takeda, "Sinusoidal current drive system of permanent magnet synchronous motor with low resolution position sensor," in Proc. IEEE 31st IAS Ann. Meeting Conf. Rec., 1996, vol. 1, pp. 9-14.

[11] R. D. Lorenz and K. W. Van Patten, "High-resolution velocity estimation for all-digital, AC servo drives," IEEE Trans. Ind. Appl., vol. 27, no. 4, pp. 701-705, Jul./Aug. 1991.

[12] Z.Feng and P.P.Acarnley, "Extrapolation technique for improving the effective resolution of position encoders in permanent-magnet motor drives," IEEE/ASME Trans. Mechatronics, vol. 13, pp. 410415, Aug. 2008.

[13] T.Emura and L.Wang, "A high resolution interpolator for incremental encoders based on the quadrature PLL method," IEEE Trans. Ind. Electron, vol. 47, pp. 84-90, Feb. 2000.

[14] C. Nasr, R. Brimaud, and C. Glaize, "Amelioration of the resolution of a shaft position sensor," in Proc. Power Electron. Appl. Conf., Antwerp, Belgium, 1985, vol. 1, pp. 2.237-2.241.

[15] A. E. Fitzgerald, Charles KingsleyJr., and Stephen D. Umans, Electric Machinery 6th edn.Beijing:Tsinghua Univ. Press, 2003. 